\title{
Como se tivesse asas nos pés: os vôos poéticos de Jandira Consuelo Brito
}

\begin{abstract}
Alessandra Bittencourt Flach*
Resumo: Este artigo analisa alguns poemas de Jandira Abstract: This paper analyzes some poems written by Consuelo Brito, senhora de 71 anos, moradora do Jandira Consuelo Brito, a 71-year-old lady and a bairro Restinga, em Porto Alegre. A escolha dessa resident of Restinga neighborhood in Porto Alegre. Our poeta desconhecida do meio acadêmico é justificada choice for this writer unknown to the academic pelo fato de ela ser um exemplo interessante de como a environment is justified by the fact that she is an poesia pode ser um instrumento de afirmação da interesting example of how poetry can be an instrument identidade. Assim, pretende-se analisar como Jandira of identity affirmation. Thus, we seek to analyze how entende a poesia e a utiliza como instrumento de auto- Jandira understands poetry and uses it as a selfexpressão, muito mais do que para obter fama ou expression instrument much more than an instrument to méritos. Apesar da pluralidade de temas, há uma get fame or merit. Despite the plurality of themes, there tendência a assuntos relacionados ao ser poeta e à is a tendency to issues related to being $a$ poet and to the liberdade de existência. Isso pode ser interpretado, de liberty of existence. This can be understood, to a certa forma, como uma maneira de, ao assumir a certain extent, as a way for her to assume the lyrical posição de eu-lírico, assumir também uma nova self position and also to assume a new attitude, a more postura, mais assertiva, em relação ao mundo à sua assertive one, concerning the world around her. volta.
\end{abstract}

Palavras-chave: poesia; Jandira Consuelo Brito; Keywords: poetry; Jandira Consuelo Brito; identity. identidade.

\author{
Há poesia \\ Na dor \\ $\mathrm{Na}$ flor \\ No beija-flor \\ No elevador \\ (Oswald de Andrade)
}

A epígrafe deste texto, uma estrofe do poema "Balada do Esplanada" (ANDRADE, 1994, p.36), tem dupla justificativa. Primeiro, expressa a multiplicidade e a abrangência das formas poéticas, o que, em certa medida, será enfocado aqui. Segundo, provocou uma interessante reflexão, que motivou o presente artigo: há uma função transformadora na poesia?

\footnotetext{
* Mestre em Literatura Brasileira pela Universidade Federal do Rio Grande do Sul (UFRGS), professora substituta de Comunicação e Expressão da ETCOM-UFRGS. Como pesquisadora, estuda as narrativas de
} 
Jandira Consuelo Pinto Brito não é nenhuma poeta famosa, também não é crítica literária, nem aspirante a uma posição acadêmica. É uma humilde senhora, de 71 anos, moradora do bairro Restinga, em Porto Alegre. Entretanto, possui uma imensa sensibilidade para as letras. É poeta. Tem dificuldade com ortografia e sintaxe, mas conhece as regras da vida, as artimanhas do destino. E sente necessidade de expressar concretamente isso, na escrita. A poesia é sua forma de manifestar esse conhecimento, de agir sobre esse destino às vezes cruel, de ser outros, de visitar um tempo que já passou e resgatá-lo, juntamente com todas as sensações que ele desperta.

Fui apresentada à Jandira numa tarde em que visitei a Restinga, em 2007, a convite da professora Ana Lúcia Liberato Tettamanzy, coordenadora do projeto "Corpo e voz em performance nas narrativas orais urbanas", do Instituto de Letras da UFRGS, que pretende, entre outras coisas, fazer um compêndio das histórias que contam os moradores desse bairro. $\mathrm{O}$ vínculo entre a academia e as pessoas fortalece-se nos encontros semanais que ocorrem na casa de um desses moradores. As conversas são sobre os mais variados assuntos, desde problemas do bairro, passando por causos da infância, até cultura e arte. Sem dúvida, são momentos de contato com experiências enriquecedoras. Jandira é uma das participantes do grupo, simpática, mas muito tímida, nem sempre entende o interesse que a "universidade" tem naquilo que ela fala ou escreve.

No entanto, foi dela que partiu o seguinte comentário": "Pois é, se eu estivesse escrito isso, não seria nada, mas, como foi escrito pelo Oswald de Andrade, é poesia”, uma alusão aos versos da epígrafe. Para ela, não estava claro o motivo pelo qual um "poeta famoso" escrevia uns versos tão desconexos, sem sentido. Afinal, em sua visão, o que tinham em comum, além da rima, as palavras “dor", “flor”, "beija-flor” e "elevador”?

Por trás desse questionamento, existe, na verdade, um discurso de autonegação. Por mais que Jandira seja reconhecida por seu esforço e dedicação, considera-se inferior, nãodigna, ou, talvez, crie essa imagem porque considera o seu saber não tão consistente quanto o saber institucionalizado. Em vários momentos, cita como suas poesias foram elogiadas ${ }^{2}$, mas, ao mesmo tempo, demonstra certo descaso com os elogios. Um exemplo interessante de como constrói seu discurso pode ser observado no seguinte diálogo dela com a pesquisadora:

Pesquisadora - Tu consegues ler, por causa do teu olho?

tradição oral e as relações da literatura com a performance que dá sentido a essas histórias; alessandraflach@bol.com.br.

${ }^{1}$ Todos os depoimentos e comentários de Jandira aqui transcritos foram registrados em vídeo, no ano de 2007.

${ }^{2}$ Jandira participava de um curso de criação literária, no bairro onde mora. 
Jandira - Consigo, pouco, mas consigo.

Pesquisadora (para filmador, que já está registrando a conversa) - Quem sabe a gente podia gravar ela lendo uns poemas?

Jandira - Ah, não, eu não sei ler, sou muito tímida. [...] Eu, quando ganhei esse certificado, tinha uma mesa assim, tinha aquele, como é, ele foi patrono da feira do livro há três anos atrás, parece....

Pesquisadora - [...] Moacyr Scliar.

Jandira - É, parece que é o Scliar. Tava lá e tudo, muita gente. E eu sou envergonhada. Me telefonaram que tinha uma homenagem pra mim. E eu digo: "Eu sou toda "escroncha", não tenho roupa boa, não tenho nada, não vou.”. E aí começaram, o telefone toda hora lá em casa, e aí minha irmã tava lá em casa de carro: "Não, tu vai". Aí eu fui, peguei o certificado, não cumprimentei ninguém, saí bem louca. Digo: "Meu Deus do céu, que que eu fiz?". A vergonha veio depois, né, porque na hora eu tava assim tão nervosa que eu peguei/. Coitada da minha professora, deve ter passado uma vergonha que/. Aí teve uma festa no/, e eu digo: "Não, eu tenho que perder isso". Aí eu declamei a "Nhá Eusébia", essa que é grande, né. Aí eu me saí bem. Mas eu sou muito tímida. Pra fotografia eu me escondo. Só num ambiente que eu me sinta bem eu sou uma tagarela. Hoje aqui eu tô me sentindo bem.

Como se pode perceber, Jandira, em vários momentos, evidencia suas limitações, sua timidez, mas também expressa certo contentamento ao descrever que seria homenageada, que houve muita insistência para que comparecesse ao evento, cujo qual contava com a presença ilustre do escritor Moacyr Scliar. Além disso, mostra sua superação ao ler uma de suas histórias em outra ocasião.

Aliás, mesmo sem se considerar escritora, mesmo afirmando não saber escrever direito, não só tem uma produção literária relativamente extensa ${ }^{3}$, mas também analisa o teor de seus textos. A seguir, resume um de seus contos e faz comentários críticos acerca do mesmo e acerca das opiniões da professora:

Tinha um guri que o guri vivia ali com eles, mas eles queriam ensinar inglês, ensinar tudo, até lit/, ããã, política elas falavam, mas foi muito bonito, porque o guri, no fim, ele vai completar os estudos, vai pra uma cidade e botam droga na mochila dele, e ele chamava pela mãe e ninguém veio e no final da história os pais dele, quando vinham vim para/, venderam tudo que tinham pra vim fazer o resgate dele e aconteceu um acidente e eles morreram. Então ele saiu da cadeia sem saber que os pais tinham morrido. É muito bonita essa história, e ela é muito grande. A minha professora disse assim: "Eu não acredito que tu tenha dois anos só de aula". Ela achou a imaginação muito/. Porque contado assim escrito é melhor, né?

O importante, a partir daí, é perceber o quanto a literatura está presente na vida de Jandira e como a "vida de escritora" tem lhe propiciado experiências inéditas. Apesar de seu discurso mostrar uma pessoa um tanto insegura e receosa aos comentários alheios, não há como negar a presença marcante da literatura como meio de obter auto-afirmação e, em certa medida, como instrumento de cidadania, em contrapartida com o discurso de Jandira, que, como já referido, tende à autodepreciação. Assim como Alfredo Bosi:

\footnotetext{
${ }^{3}$ Tive acesso, para a produção deste artigo, a mais de 40 poemas, manuscritos nas páginas de uma agenda velha. Alguns foram elaborados nas oficinas de criação literária, mas a maioria havia sido produzida de forma voluntária, sem exigência da professora
} 
Parto da hipótese de que é possível identificar, na dinâmica dos valores vividos em contextos de pobreza, certas motivações que levem à atividade social da leitura e da escrita. Trata-se de descobrir o leitor-escritor potencial. O que me move é pensar o excluído como agente virtual da escrita, quer literária, quer não literária. [...] Nesse horizonte, atos de ler e de escrever podem converter-se em exercícios de educação para a cidadania. (BOSI, 2002, p. 261)

Assim, Jandira Consuelo Pinto Brito, ou melhor, a obra poética de Jandira foi escolhida como objeto de análise. Não se pretende, com isso, fazer de seu biografismo o foco deste trabalho. Da mesma forma, não será feita apologia a sua condição pobre e marginalizada como "bandeira" para divulgar as vozes da periferia e sua luta de sobrevivência. O que se busca é analisar literariamente a obra de Jandira, especificamente no que se refere à forma como o eu-lírico define o ser poeta e a função da poesia, já que a própria introduz o assunto, ao estipular, a partir de uns versos de Oswald, o que considera poesia.

A partir de versos selecionados, foi possível perceber uma tendência a temas como saudade, natureza, retorno à infância, passagem do tempo, permanência do ser, busca por liberdade, todos os quais, quase sempre, relacionados ao "fazer poético", quer dizer, à poesia como instrumento de permanência, de aproximação com a natureza, de libertação. O que predomina é a voz forte de um "eu" em busca de experiências libertadoras, redentoras. Em certa medida, há uma aproximação com o conceito de "lirismo vivencial" mencionado por Käte Hamburger:

\footnotetext{
empregado para designar o lirismo do sentimento pessoal e a expressão poética dos sentimentos que se iniciou no fim do século XVIII, contrastando com o lirismo essencialmente convencional, de cunho social e formal de épocas anteriores. O conceito de "vivência" é compreendido aqui psicológica e biograficamente. [...] A vivência pode ser "fictícia" no sentido de invencionada mas o sujeito vivencial e com ele o sujeito-de-enunciação, o eu lírico, pode existir somente como um real e nunca fictício. (HAMBURGER, 1986, p.198-199)
}

Isso leva a concluir que, mesmo se as situações e as emoções não forem vividas, de fato, pelo sujeito vivencial, a poeta, há, na poesia, esse "lirismo vivencial", ou seja, a percepção de um sujeito real que se expressa através da percepção de um eu-lírico. No entanto, é importante repetir, seria superficial demais interpretar isso como a correspondência direta entre as emoções e vivências da pessoa que escreve e as do eu-lírico. Há, sem dúvida, uma aproximação, uma presença (nem sempre tão evidente) da poeta Jandira na expressão do eu-lírico. Todavia, ocorre uma transformação, o discurso pessoal, real, passa a arte, poema. Com isso, a própria função da linguagem altera-se. E não faz sentido buscar nessa relação mais do que influências recíprocas. O poema adquire independência de seu criador, como a própria poeta reconhece, nos seguintes versos:

Meus versos são como um filho 
Bota-se no mundo criam asas

E voam

Voam sempre sem parar

Vão para tão longe

Vão ao busca de liberdade

E de um mundo novo para ficar

A comparação dos versos com o filho incontível, que vai em busca de novas experiências, é uma boa imagem para explicar o conceito de "lirismo vivencial". No filho, mesmo já dispondo de autonomia, está a marca do progenitor, mas de uma forma às vezes um tanto distorcida. E este permanece naquele, fazem parte um do outro, ainda que o foco seja o segundo. Ou seja, o poema deve falar por si, contém tudo de que necessitamos para entendêlo, independentemente do que fez ou pensou aquele que o compôs, apesar de sua presença estar registrada de alguma forma nesses versos que "voam sempre sem parar".

Aliás, pode-se considerar que o eu-lírico, na quase totalidade das poesias, tem um olhar para o alto, pretende alcançar o céu. $\mathrm{O}$ voar, imagem reincidente em vários versos, é a expressão da libertação almejada, a libertação de uma vida de sofrimentos e limites. Da mesma forma, representa uma maneira de ser desvinculada de qualquer estereótipo ou fatum. Daí a identificação com a natureza, com animais, que têm autonomia e soberania pelas próprias características, como em:

Quero ser uma borboleta

Voar voar sem saber

Onde chegar

E bem alto ver rosas desabrochar

Ou:

Eu nasci nos verdes campos

Eu cresci entre as colinas

Viajei nos lagos mansos

Sou filha da natureza

Sinto o vento nas campinas

Adoro a vida que tenho

Quando a noite habita os campos

Sigo o vento serra acima.

É interessante notar, também, que a mesma natureza que leva à viagem, à liberdade, que constitui o modelo ideal de vida, pode ser símbolo de ascensão e declínio:

A nossa vida é como uma árvore

Nós quando crianças somos acariciados

Cuidados para crescer

A árvore quando nova é cuidada

Até sua velhice e cortada e

Vai para o fogo 
A melhor interpretação para esse poema, que expressa a passagem do tempo, do apogeu da infância, acariciada, até a morte impiedosa, talvez seja esta explicação poética, nos versos de “Tempo”, de Manoel de Barros (2006):

Eu não amava que botassem data na minha existência. A gente usava mais era encher o tempo. Nossa data maior era o quando. O quando mandava em nós. A gente era o que quisesse ser só usando esse advérbio. Assim, por exemplo: tem hora que eu sou quando uma árvore e podia apreciar melhor os passarinhos. [...] Quem é quando criança a natureza nos mistura com as suas árvores, com as suas águas, com o olho azul do céu. Por tudo isso que eu não gostasse de botar data na existência. Por que o tempo não anda pra trás. Ele só andasse pra trás botasse a palavra quando de suporte. (BARROS, 2006, s.p.)

Jandira, ao transferir-se para a voz do eu-lírico, também busca esse quando.. A partir dele, quase como uma palavra mágica, consegue tornar-se outros, ver como as coisas seriam e se comportariam sob um ângulo diferente. Certa acidez no tom ao constatar a passagem de uma época à outra (em que a árvore "é cortada e vai para o fogo") expressa a melancolia do eu-lírico ao falar da velhice, mas, em contrapartida, ao falar da infância, como nos versos de Manoel de Barros, volta a ela, e, junto, retornam o entusiasmo e a vitalidade. Não existe, portanto, uma visão utópica da vida, como algo maravilhoso e indefectível. Existe o desejo por essa plenitude, mas, ao mesmo tempo, forte consciência da realidade, muito contrastante com o sonho.

\footnotetext{
Vou pouco a pouco à procura do nada

Feliz quem tem carinho e família

Infeliz quem não tem nada

Devo sumir como água em mãos fechadas

Ou devo bater asas e continuar a jornada

Ou devo continuar bater de porta em porta

Eu continuo ando continuo

Saibam, a vida é uma grande jornada
}

Aliás, parece ser justamente essa noção de oposição entre sonho e realidade que move o fazer poético. Se o objeto ideal é inalcançável, a tristeza que surge da percepção do impossível é a essência da própria poesia. Dois exemplos bastante ilustrativos podem ser citados:

\author{
Eu adoro a poesia \\ Porque ela me faz bem \\ Quando me sinto triste \\ Sou poeta como ninguém \\ Dizem que há mais \\ Mundos lá fora \\ Os quais eu nunca vi \\ Do que me vale tudo isso
}




\title{
Se meu mundo é aqui
}

No primeiro poema, a tristeza é o sentimento que incentiva a produção da poesia. Mais do que isso: é a alternativa para superar a tristeza. Aqui fica claro que o exercício poético é um meio de transcender uma sensação negativa, superar uma situação de debilidade emocional. Daí talvez a possibilidade de explicar o motivo pelo qual "voar", "vento", "flores desabrochando" sejam imagens recorrentes na obra de Jandira. Se o fazer poético, segundo o eu-lírico, permite extravasar sentimentos negativos, então nada mais coerente do que empregar uma temática que crie efeitos de liberdade, felicidade e extrapolação de limites.

No segundo exemplo, nota-se essa dicotomia entre o "aqui", mundo limitado, e o "lá fora", lugar de possibilidades, expresso, inclusive, pela palavra "mundos", no plural. Essa constatação, que, ao mesmo tempo, permite ver além, mas também a condição presente, reforça claramente o descontentamento em relação a esta última. De certa forma, não deixa de ser um desabafo do eu-lírico, uma manifestação de seu conflito acerca da impossibilidade de avançar, de experimentar outras sensações. Há um interesse pelo outro, em associação com a permanência do ser.

Todavia, o poema que reúne de forma definitiva essa idéia de sonho e realidade, de desejo por avançar é este:

\author{
Sou um sonhador \\ Onde o vento me levar eu vou \\ Vou em busca das perguntas \\ Que me fiz \\ Talvez encontre as respostas \\ Mas o vento voltará e me levará \\ Para um mundo que sonhei \\ Quero voar sem saber onde chegar \\ E lá bem alto ver rosas desabrochar
}

Nele, o eu-lírico assume abertamente sua condição de sonhador, ou seja, vive em uma realidade que não o satisfaz, cuja existência só poderá ser plena apelando-se para o sonho. Contudo, não é um sonho alienante, sonho-fuga. Ele tem seus objetivos ("Vou em busca das perguntas que me fiz”). Para tanto, é preciso voar, distanciar-se de uma condição prévia, ter autonomia, buscar uma visão até um pouco distanciada das coisas para melhor as interpretar.. O sonho, que também pode ser interpretado como o próprio exercício poético, ao contrário do que se poderia considerar, possibilita uma compreensão muito mais lúcida do que a própria realidade, já que esta impõe condições para o existir, delimita formas de pensar, convencionaliza. Isso cria uma imagem deturpada do sujeito, que precisa buscar no sonho meios mais autênticos de expressão. 
O "lirismo vivencial", que se repete em inúmeros poemas da obra de Jandira, tende a reiterar, sob as mais diversas imagens e simbologias, um desejo por liberdade, em um sentido quase espiritual. A forte subjetividade traz à luz um sujeito sufocado por uma vivência opressiva, que tolhe sentimentos, que impede a livre manifestação das vontades. O que é colocado em xeque é o efeito dessa opressão, jamais sua(s) causa(s). Todavia, em vez de isso constituir um eu-lírico descrente e pessimista, ou até conformado, tem-se a contemplação de um espaço ideal, há perspectivas de transcender, mesmo que somente em intenção, apesar, como já referido, da consciência de sua realidade. A síntese dessa idéia está no seguinte poema, quase um manifesto:

\footnotetext{
Quero que todos me ouçam

E me compreendam

Depois tudo vai calar

Assim eu vou respirar

Vou me sentir mais livre

Para de novo gritar
}

O grito é emblemático. Representa a possibilidade de, mesmo que por apenas alguns instantes, expressar-se, comunicar algo, chamar a atenção para determinada situação. Há, aqui, um interessante contraste: o grito constitui o clímax de um desespero; por outro lado, esse extravasamento leva à calma, ao silêncio, à serenidade ("Depois tudo vai calar/Assim eu vou respirar"). Tal tranqüilidade, obtida a partir do efeito libertador do grito ("Vou me sentir mais livre"), não é permanente, porque logo reaparece a necessidade de gritar. Isso leva a perceber que a situação que motivou o desespero e o grito repete-se, reavivando o interesse por fazer-se ouvir. Mais do que isso, constata-se certa consciência social, na medida em que se expressa um interesse por que as pessoas "ouçam" e "compreendam". Não é a simples manifestação de sentimentos pessoais, mas uma manifestação que visa ao outro, como se fosse um alerta sobre algo.

No que se refere à condição do poeta, o sentido da existência, da condição de ser poeta, está voltado para uma realização pessoal, relacionada muito mais a uma autogratificação do que à notoriedade:

\footnotetext{
O sonho de um poeta

Não é medalha de atleta

O sonho do poeta é ver rosas

Se abrir

E ver crianças sorrir
} 
Novamente, está subentendido que o exercício poético permite vivenciar sensações que de outra forma não seria possível. O poeta é um privilegiado. Só ele parece perceber beleza nas coisas simples da vida. Seu ângulo de visão é mais sensível, mais perspicaz. O lirismo aplicado ao cotidiano, através do trabalho sobre a linguagem, transforma a realidade, destaca-a, torna-a mais vívida. Dessa forma, "ver rosas se abrir”"4 e "ver crianças sorrir" são ações que transcendem a banalidade do cotidiano quando abordadas sob status de poesia. $\mathrm{O}$ poeta, que se eterniza em seus versos, torna-se grande ao valorizar o detalhe. Sem dúvida, age sobre o banal através da poesia. Em certa medida, essa também é a visão de Oswald de Andrade, em outros versos do poema "Balada do Esplanada", citado pela própria Jandira. O que ele faz, na poesia, também é atribuir lirismo e beleza ao cotidiano e, com isso, eternizarse:

Eu qu'ria
Poder
Encher
Este papel
De versos lindos
É tão distinto
Ser menestrel
No futuro
As gerações
Que passariam
Diriam
É o hotel
Do menestrel

A diferença entre a poesia de Jandira e a de Oswald, a partir do contraponto desses versos, ou seja, da visão de seus respectivos eu-líricos, está no fato de que ela faz poesia, principalmente, para si mesma, como forma de expressar-se sem reprimendas sociais ("O sonho de um poeta/Não é medalha de atleta"), ao passo que ele, como expresso nos últimos versos, visa ao reconhecimento futuro. Entretanto, o que Jandira parece não aceitar é uma vulgarização da poesia, vulgarização essa menosprezada no seu comentário sobre os versos de Oswald ("se eu estivesse escrito isso, não seria nada, mas, como foi escrito pelo Oswald de Andrade, é poesia"). Para ela, poesia mesmo tem de ter sentimento explicitamente declarado. E isso pode ser notado em todas as poesias aqui citadas, as quais tendem a elaborar as mais

\footnotetext{
${ }^{4}$ Mais uma vez, a imagem das rosas que desabrocham, a idéia de mutação, de aprimoramento e plenitude. É interessante notar a quantidade de poemas em que esse símbolo aparece. É, sem dúvida, bastante representativo da poesia de Jandira.
} 
diversas formas de sentimento, em uma estrutura tradicional de versos e estrofes ${ }^{5}$. Além disso, refere que a rima (“dor", "flor”) e a disposição em verso não garantem o lirismo. Há que se ter, além disso, uma subjetividade maior, inclusive para falar do cotidiano.

Portanto, como ela mesma emprega em seus versos, o mais importante é a subjetividade, expressa pela presença constante do eu-lírico. Ela é muito mais romântica do que modernista ou concretista. Daí a dificuldade em sensibilizar-se com os versos de Oswald, que significam a partir de uma leitura que busca sentidos além do que está escrito, apresentando uma unidade através da fragmentação e da heterogeneidade dos elementos mencionados. Todavia, apesar dos abismos que os separam, Oswald dialoga muito mais com sua poesia do que Jandira poderia considerar em princípio. Como ela, ele também defende "A Poesia para os poetas. Alegria dos que não sabem e descobrem" (ANDRADE, 1995, p.41) e empenha-se em valorizar "o contrapeso da originalidade nativa para inutilizar a adesão acadêmica" (ibid. p.45), tal como Jandira tão bem executa.

Como ela própria ensina em seus versos, em que outra forma melhor do que na poesia seria possível realizar o desejo de "ser livre e correr como se tivesse asas nos pés"? E isso se concretiza tanto a partir da leitura de grandes nomes de nossa literatura quanto nos versos da tímida e cativante Jandira.

\title{
Referências
}

ANDRADE, Oswald de. A utopia antropofágica. 2 ed. São Paulo: Globo, 1995. 1994.

Primeiro caderno do aluno de poesia Oswald de Andrade. 2 ed. São Paulo: Globo,

BARROS, Manoel. Memórias inventadas: a segunda infância.. São Paulo: Editora Planeta do Brasil, 2006.

BOSI, Alfredo. Literatura e resistência. São Paulo: Companhia das Letras, 2002.

HAMBURGER, Käte. A lógica da criação literária. São Paulo: Perspectiva, 1986.

\footnotetext{
${ }^{5}$ Ainda que, como se pode constatar, tem certa dificuldade em definir, de forma criteriosa, onde um verso acaba e começa o outro. Em muitos de seus poemas, o desejo por compor os versos e as estrofes interferem negativamente na unidade de sentidos, como neste caso:
}

\author{
Você é um desejo que me \\ Faz acordar \\ Você é a luz que me faz enxergar \\ Você é o mel que adoça \\ Minha vida
}

